\title{
A brewing public health crisis: antibiotic resistance
}

\author{
N. Adhikari \\ Patan Academy of Health Sciences \\ Correspondence to: Dr. Neelam Adhikari, Rector, Patan Academy of Health Sciences \\ e-mail: neelamadhikari@gmail.com
}

\begin{abstract}
"Antibiotics" have always been a symbol of miracles of modern medicine, saving innumerable lives and literally changing world of medicine. Even in the era of extremely glamorous robotic surgery antibiotics have never been undervalued by physicians and surgeons alike. It began in 1928 when bacteriologist Alexander Fleming serendipitously realized that the growth of Staphylococcus aureus was inhibited in a petri dish contaminated by mold. Within a few years we had sulfa drugs; rapidly followed by more effective beta-lactams, chloramphenicol, tetracycline, and by 1950 , the aminoglycosides.
\end{abstract}

Scientists discovered newer drugs. Unfortunately all was not well. While making an attempt to control an infection, before an organism was identified or even before such an attempt was made, it became a common practice to give broad spectrum antibiotics. This 'innocent' use of broad spectrum antibiotics caused natural evolution of the microbes, which escaped unhurt. Microbes developed resistance to our weapons.

In process of treating more and more patients with newer technologies, we used old and new antibiotics more and more intensively. After all, we were now treating sicker patients. But antibiotics are unlike any other drug, in that the use of the drug in one patient can compromise its safety in another. Other unique feature of antibiotics is that what is effective today, will not be effective in 15-20 years from now. The battle between humans and bacteria led to an alarming increase in resistance to all clinically useful antibacterial agents, Dangerous and multiply resistant organisms appeared. On many occasions previously treatable infections now became untreatable. The treatment costs also skyrocketed.

\section{How did it come about?}

1. Only very few of general public is aware of this catastrophe. Their faith in antibiotics remains undiminished. Many believe they can cure any disease, ameliorate the symptoms and even prevent the infections. Pushy patients would force the physician to prescribe antibiotics.

2. Do the doctors do a good job in explaining?

Many write antibiotics even for self limiting viral infections, do not keep up with advances in field of antibiotics and give the newest, most potent agent in any dose and duration. Some physicians prescribe antibiotics, not wanting to make their patients angry or fearing accusation of negligence. A perceived conflict between what is best for a patient and what is best for public health, encouraged irrational use of antibiotics.

3. Pharmaceutical detailing is aggressive and falling in trap is easy.

4. Farmers used tons of antimicrobials in animal feed and water to promote animal growth. Many of the antibiotics used in this setting are of the same class as those used to treat human infections, such as macrolides, tetracycline, glycopeptides. The use of glycopeptides, avoparcin, in animal feed is believed to be responsible for the emergencece of Vancomycin Resistance Enterococcus (VRE).

\section{Bacterial statergies}

1. Reduced outer membrane permeability

2. Reduced cytoplasmic membrane transport

3. Increased efflux/decreased influx of antibiotic

4. Neutralization of antibiotic by the enzyme

5. Target modification and

6. Target elimination

What would have helped is that we increased our capability to make a quick microbiological diagnosis along with sensitivity and minimum inhibitory concentration estimation. Considerable advances have been made in this regard too. However we still do not get instantaneous answers and these are expensive and not available at most places 
The most serious, life threatening infections are caused by a group of drug-resistant bacteria that the Infectious Disease Society of America (IDSA) has labeled the "ESKAPE" pathogens, because they effectively escape the effects of antibacterial drugs.

These are-

E- Enterococcus faecium

S- Staphylococcus aureus (MRSA)

K-Klebsiella pneumoniae, Escherichia coli

A-Acenetobacter baumanni

P-Pseunomonas aerugenosa

E-Enterobacter species.

Number of such resistant organisms is feared to increase geometrically

\section{Development of newer antibiotics:}

It is not that that there aren't any antibiotics in development. It takes at least nine years between discovery and launch of a new antibiotic. The economic and regulatory climate has changed. There is increased complexity and cost of drug trials. Pharmaceutical companies are shifting from developing newer antibiotics because of their becoming auto -obsolete, more financial incentive in developing drugs for elderly, chronic diseases and life style drugs such as depression, obesity, impotence, and dementia.

\section{What has been done?}

The IDSA has launched an initiative that it hopes will invigorate the process. On November 20,2009 IDSA sent a letter to President Barrack Obama and to Prime Minister Fredrik Reinfeldt, representing European Union(EU ) presidency to request a commitment to develop 10 novel antibacterial drugs by the year $2020(10 \times 20)$. There is precedence of success in having several new anti tubercular drugs in pipe line because of formation of TB Alliance (www.tb.org).

\section{What can we do?}

Apart from following infection control practices meticulously and using antibiotics judiciously, we should work hard on increasing awareness of this issue among the medical community. Political and scientific forces in developed countries must get together to recognize scope of problems and find solutions.

It is just not our patients who are at risk. It is all of us.

\section{References}

1. Livermore DM. Has the era of untreatable infections arrived? J Antimicrob Chemotherapy 2009;64 (Suppl 1):29-36.

2. Boucher HW. Talbot GH, Bradley JS,et al. Bad bugs, no drugs, no ESKAPE! An update from the Infectious Diseases Society of America. Clin Infect Dis. 2009; 48:1-12.

3. Chen LF, Chopra T, Kaye KS. Pathogens resistant to antibacterial agents. Infect Dis clin N Am. 2009; 23:817-845.

4. Neil S. Ryder. Discontinued drugs in 2008; antiinfectives. Expert opinion on Investigational Drugs.2010; 19(1): 1-21. 